\title{
Energy conservation in hibernating endotherms: Why "suboptimal" temperatures are optimal
}

\author{
Justin G. Boyles*, Andrew E. McKechnie \\ DST/NRF Centre of Excellence at the Percy FitzPatrick Institute, Department of Zoology and Entomology, University of Pretoria, Pretoria 0002, South Africa
}

\section{A R T I C L E I N F O}

\section{Article history:}

Received 15 January 2010

Received in revised form 9 March 2010

Accepted 19 March 2010

Available online $\mathrm{xxx}$

\section{Keywords:}

Endotherms

Heterothermy

Hibernation

Thermoregulation

Torpor

\begin{abstract}
A B S T R A C T
Many endotherms use facultative heterothermic responses of torpor or hibernation to conserve energy during periods of low energy availability. A common assumption when estimating winter energy budgets is that endotherms should hibernate at the ambient temperature $\left(T_{a}\right)$ that minimizes torpid metabolic rate (TMR) and maximizes the duration of torpor bouts. However, previous studies of the energetic benefits of hibernation have assumed constant $T_{\mathrm{a}}$ within hibernacula. Here we use an individual-based energetic model to estimate overwinter energy expenditure of mammals hibernating at $T_{\mathrm{a}} \mathrm{s}$ that vary temporally. We show that, in accordance with the principles of Jenson's inequality, hibernators can conserve energy by selecting microclimates warmer than the single $T_{\mathrm{a}}$ value that minimizes TMR $\left(T_{\min }\right)$. As temporal variation in $T_{\mathrm{a}}$ increases, endotherms should choose microclimates with mean $T_{\mathrm{a}} \mathrm{s}$ progressively warmer than $T_{\min }$. Further, as thermal conductance decreases, as it does with increasing body mass and use of social thermoregulation, the mean $T_{\mathrm{a}}$ that minimizes overwinter energy expenditure approaches, but never equals, $T_{\min }$. We suggest that the commonly held assumption of stable microclimates in hibernacula has skewed the interpretation of the optimal expression of hibernation for energy conservation. Our results contradict much of the accepted understanding of hibernation energetics and add to a growing body of literature proposing that hibernating at a $T_{\mathrm{a}}$ warmer than $T_{\min }$ is optimal.
\end{abstract}

(c) 2010 Elsevier B.V. All rights reserved.

\section{Introduction}

Many mammals use facultative heterothermic responses (torpor and/or hibernation) to reduce metabolic demands during periods of low energy availability. Because the primary benefit of facultative heterothermy is thought to be energy conservation, most studies have focused on quantifying the relationship between ambient temperature $\left(T_{\mathrm{a}}\right)$ and torpid metabolic rate (TMR) (e.g., Geiser, 2004; Willis et al., 2005; Dunbar and Tomasi, 2006). During torpor and hibernation, endotherms defend a reduced body temperature $\left(T_{\mathrm{b}}\right)$ setpoint that may be as much as $40^{\circ} \mathrm{C}$ below normothermic levels, with fundamentally different $T_{\mathrm{a}}$-TMR relationships above and below the $T_{\mathrm{a}}$ where TMR is minimized $\left(T_{\min }\right)$. At $T_{\mathrm{a}}>T_{\min }$, TMR decreases with $T_{\mathrm{a}}$, typically with $Q_{10}$ values of $2-3$ (Geiser, 2004). At $T_{\mathrm{a}}<T_{\min }$, TMR increases linearly with decreasing $T_{\mathrm{a}}$ as animals increase metabolic thermogenesis in order to defend their $T_{\mathrm{b}}$ and avoid freezing if $T_{\mathrm{a}}$ falls below freezing (Buck and Barnes, 2000). Many researchers have argued that, in order to minimize TMR and maximize energy conservation, selection of microclimates in which $T_{\mathrm{a}} \approx T_{\min }$ is preferred and even optimal for

\footnotetext{
* Corresponding author. Tel.: +27 124203232.

E-mail address: jgboyles@zoology.up.ac.za (J.G. Boyles).
}

hibernating mammals (e.g., Körtner and Geiser, 1998; Dunbar and Tomasi, 2006). However, recent theoretical and experimental work suggests that the benefit of energy conservation is counteracted by physiological and ecological costs associated with maintaining a low $T_{\mathrm{b}}$, and that the optimal cost-benefit ratios are in reality attained by hibernating at $T_{\mathrm{a}} \mathrm{s}$ higher than $T_{\min }$ (Humphries et al., 2003; Boyles et al., 2007; Angilletta et al., forthcoming). Admittedly, this view is based largely on assumptions, rather than empirical evidence, because the costs have only relatively recently received attention from researchers (Angilletta et al., forthcoming).

Importantly, the prediction that hibernating mammals should choose microclimates warmer than $T_{\min }$ can be made on the basis of energetic considerations alone. In other words, it is not be necessary to invoke non-energetic costs to argue that the "optimal" $T_{\mathrm{a}}$ for hibernation is actually "suboptimal" in terms of overall energy conservation. Instead, we can use the principles of Jenson's inequality, which is a mathematical proof that has important implications when analyzing non-linear relationships (Ruel and Ayres, 1999). When applied to biological systems it states, inter alia, that predicting optimal behavior cannot be done from mean values alone but also depends heavily on the variance and skewness of the relationships in question (Martin and Huey, 2008). Ruel and Ayres (1999) suggest that variance in $T_{\mathrm{b}}$ increases metabolic rate and Martin and Huey (2008) show that skewed performance curves in 
ectotherms combine with imperfect thermoregulation to result in the optimal expression of $T_{\mathrm{b}}$ being below the value that maximizes performance.

In theory, similar principles should hold for predicting "optimal" hibernating microclimates for energy conservation, because the relationship between $T_{\mathrm{a}}$ and TMR is also a skewed, non-linear relationship. Specifically, the fractional increment in TMR associated with a decrease in $T_{\mathrm{a}}$ of $X^{\circ} \mathrm{C}$ below $T_{\min }$ is greater than the increment associated with an increase in $T_{\mathrm{a}}$ of $X^{\circ} \mathrm{C}$ above $T_{\min }$. It would be easy to qualitatively extend the results of Ruel and Ayres (1999) and Martin and Huey (2008) to hibernating endotherms but the piecewise nature of the formulae relating $T_{\mathrm{a}}$ to TMR and torpor bout duration necessitates a more quantitative approach. Here, we report the results of an individual-based modeling exercise which shows that, for the purposes of energy conservation, variation in $T_{\mathrm{a}}$ in hibernacula leads to an optimal hibernating $T_{\mathrm{a}}$ above $T_{\min }$.

\section{Materials and methods}

We modified an energetic model used previously to estimate overwinter energy expenditure (Humphries et al., 2002; Boyles and Brack, 2009; Boyles and Willis, 2010). We applied the model to a typical hibernating species, the little brown bat (Myotis lucifugus), but we purposely generalized the model such that our results are not highly accurate representations of hibernation by little brown bats, but are instead a proof of point that can be conceptually applied to any hibernating species. With only minor exceptions (see below), we followed the modeling technique, including parameter values, ${ }^{1}$ of Humphries et al. (2002). This basic model has been improved upon elsewhere (Boyles and Brack, 2009; Boyles and Willis, 2010), but these improvements are unnecessary to make the present point. Briefly, the model estimates energy expended each hour over the course of winter. During hibernation, fat is metabolized at a rate determined by TMR. Periodically, the animal arouses to euthermic $T_{\mathrm{b}}$ and fat is metabolized at resting metabolic rate for $3 \mathrm{~h}$ (Thomas et al., 1990; Humphries et al., 2002). Energy expenditure during the warming phase of arousal is calculated as the energy necessary to warm from torpid $T_{\mathrm{b}}$ to euthermic $T_{\mathrm{b}}$ and the cooling phase is calculated as $67 \%$ of the warming phase (Thomas et al., 1990). We conducted all simulations in Python 2.6.4. A complete description of the model and computer simulation techniques are available in Boyles and Brack (2009).

To simulate variation around the mean $T_{\mathrm{a}}\left(T_{\text {mean }}\right)$ we included two new variables in the model, namely temperature change per hour $\left(\Delta T_{\mathrm{a}} ;{ }^{\circ} \mathrm{C} / \mathrm{h}\right)$ and a range of values over which $T_{\mathrm{a}}$ can fluctuate $\left(T_{\text {breadth }}\right)$. For each hour, the model randomly chooses a $\Delta T_{\mathrm{a}}$ within the bounds of each simulation $\left( \pm 0.01,0.1,0.25,0.5\right.$, or $\left.1{ }^{\circ} \mathrm{C} / \mathrm{h}\right)$ and adds that value to the $T_{\mathrm{a}}$ from the previous hour, essentially creating a "random walk" bounded by $T_{\text {breadth }}$ at one of three levels $\left( \pm 1,5\right.$, or $10^{\circ} \mathrm{C}$ around $\left.T_{\text {mean }}\right)$. If the $T_{\mathrm{a}}$ chosen for a given hour is outside $T_{\text {mean }} \pm T_{\text {breadth }}$, then a new $T_{\mathrm{a}}$ is chosen. If this $T_{\mathrm{a}}$ is also outside $T_{\text {mean }} \pm T_{\text {breadth }}, T_{\mathrm{a}}$ is set at $T_{\text {mean }} \pm T_{\text {breadth }}$ for that hour. Because the pattern in $T_{\mathrm{a}}$ variation is random for each individual, $T_{\text {mean }}$ is not controlled in the model and simulations can result in $T_{\text {mean }}$ values that depart from a specific $T_{\text {mean }}$ of interest. To ensure an adequate number of simulations for each $T_{\text {mean }}$ value, we discarded any simulations that yielded $T_{\text {mean }}$ values that differed by more than $0.25^{\circ} \mathrm{C}$ from the $T_{\text {mean }}$ of interest, and repeated the simulations until we had modeled energy expenditure for 100

1 Parameter values can be found in the supplementary materials of Humphries et al. (2002) at http://www.nature.com/nature/journal/v418/ n6895/suppinfo/nature00828.html. individuals at each $T_{\text {mean }}$ value. The magnitudes of $T_{\mathrm{a}}$ variation we have modelled are representative of the range of microclimates experienced by hibernating endotherms in a variety of habitats (Supplementary materials), although the patterns of variation may not necessarily be representative of natural environments. In reality, the temporal variation in $T_{\mathrm{a}}$ experienced by many hibernating endotherms may be better described by functions other than a random walk, and different environments are likely to have different patterns of "noise" in $T_{\mathrm{a}}$ (Vasseur and Yodzis, 2004). While more realistic patterns of $T_{\mathrm{a}}$ variation should be considered in species/population-specific models of hibernation energetics, our goal in this paper is merely proof of concept, so we have chosen a straightforward modeling technique to describe patterns of $T_{\mathrm{a}}$.

To demonstrate the effects of changing the relative slopes of the relationships between $T_{\mathrm{a}}$ and overwinter energy expenditure, we also modeled the effect of changing thermal conductance, which affects TMR when $T_{\mathrm{a}}<T_{\min }$, but not when $T_{\mathrm{a}}>T_{\min }$; under the latter conditions TMR is directly dependent on $T_{\mathrm{b}}$ rather than rates of heat loss, whereas when $T_{\mathrm{a}}<T_{\min }$ a $T_{\mathrm{b}}$ setpoint is defended by means of metabolic thermogenesis (Heldmaier and Ruf, 1992). Specifically, increasing thermal conductance increases the cost of hibernating at $T_{\mathrm{a}} \mathrm{s}$ cooler than $T_{\min }$ but not the cost of hibernating at $T_{\mathrm{a}} \mathrm{s}$ warmer than $T_{\text {min }}$. Changing thermal conductance can represent several important aspects of hibernation energetics. For example, thermal conductance scales allometrically, with larger species having lower thermal conductance (Geiser, 2004), and huddling during hibernation lowers effective thermal conductance (Boyles et al., 2008). We modeled thermal conductance at three levels $(0.007,0.07$, and $0.7 \mathrm{ml} \mathrm{O}_{2} /\left(\mathrm{g} \mathrm{h}^{\circ} \mathrm{C}\right)$ ), which span the range of values found in hibernating mammals (Geiser, 2004).

We modified Humphries et al.'s (2002) model in two ways. First, we did not model mass-dependent effects, i.e., our model calculates $\mathrm{mg}$ of fat metabolized over the course of winter per $\mathrm{g}$ of body mass at the beginning of winter. This simplification changes the slopes of curves, but not the $T_{\mathrm{a}}$ associated with minimum energy expenditure, which was the variable of interest in our analyses. Second, because we modeled fluctuating $T_{\mathrm{a}}$, the formulae used by Humphries et al. (2002) for calculating torpor bout durations are not applicable. Instead, we followed these authors in assuming torpor bout durations are determined by energy expenditure (as measured via oxygen consumption), and calculated oxygen consumed at minimum TMR $\left(0.03 \mathrm{mlO}_{2} /(\mathrm{gh})\right)$ over the course of a torpor bout of average length $(792 \mathrm{~h})$. Thus the model simulates an arousal each time $23.76 \mathrm{ml} \mathrm{O}_{2}$ is consumed.

\section{Results}

As reported elsewhere (Humphries et al., 2002), hibernating at $T_{\mathrm{a}}=T_{\min }$ minimizes overwinter energy expenditure in a constant thermal environment (Fig. 1). Fluctuating $T_{\mathrm{a}}$ has two effects on energy expenditure. First, energy expenditure increases when compared to constant $T_{\mathrm{a}}$. Second, even small fluctuations in $T_{\mathrm{a}}$ over the course of winter make the optimal $T_{\text {mean }}$ for energy conservation warmer than $T_{\text {min }}$ (Fig. 1 ). Optimal $T_{\text {mean }}$ increases as maximum $\Delta T_{\mathrm{a}}$ increases, but the relationship is not linear because optimal $T_{\text {mean }}$ reaches a plateau (Fig. 2). Generally speaking, the plateau occurs at a $T_{\text {mean }}$ such that any temperatures below $T_{\text {min }}$ are either excluded completely (e.g., when $T_{\text {breadth }}=1$, optimal $T_{\text {mean }}$ is $T_{\min }+1{ }^{\circ} \mathrm{C}$ ) or at the extreme of possible $T_{\mathrm{a}} \mathrm{S}$ as necessitated by $T_{\text {breadth }}$ (e.g., when $T_{\text {breadth }}=5$, optimal $T_{\text {mean }}$ is $T_{\min }+4^{\circ} \mathrm{C}$ ). The requirement of the model that $T_{\text {mean }}$ for the winter is within $\pm 0.25^{\circ} \mathrm{C}$ of the desired mean $T_{\mathrm{a}}$ ensures that extreme temperatures would rarely be experienced anyway. Increasing thermal conductance leads an increase in the $T_{\text {mean }}$ that minimizes overwin- 


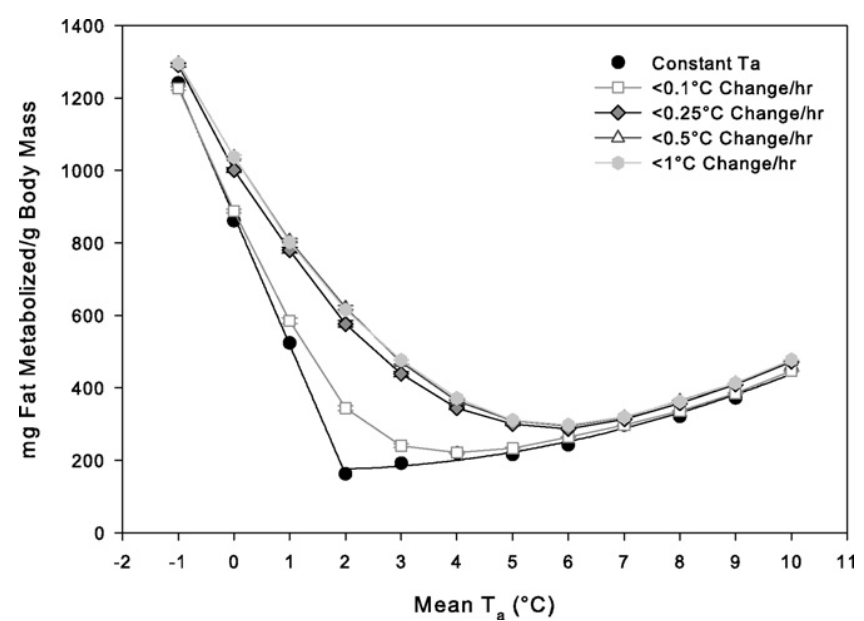

Fig. 1. Body mass-independent energy expenditure over the course of a 193-day winter for a representative mammalian hibernator, Myotis lucifugus. This simulation represents an environment in which $T_{\mathrm{a}}$ can vary up to $5^{\circ} \mathrm{C}$ above or below the mean $T_{\mathrm{a}}$ value. The lines correspond to the fat metabolized at various rates of change in $T_{\mathrm{a}}$. Thermal conductance was set at $0.055 \mathrm{ml} \mathrm{O}_{2} /\left(\mathrm{g} \mathrm{h}^{\circ} \mathrm{C}\right.$ ) (Humphries et al., 2002).

ter energy expenditure with values increasing as maximum $\Delta T_{\mathrm{a}}$ increases (Fig. 3).

\section{Discussion}

Using a well established modeling technique, we show that the mean $T_{\mathrm{a}}$ that minimizes energy expenditure over the course of hibernation is above $T_{\min }$ if there is any temporal variation in $T_{\mathrm{a}}$. Since variation in $T_{\mathrm{a}}$ occurs in even the most stable hibernacula, including burrows (Buck and Barnes, 1999) and caves (Brack, 2007), we predict that energetically ideal hibernacula are those with microclimates generally warmer than $T_{\min }$. This prediction arises from the energetic inequality of fluctuations in $T_{\mathrm{a}}$ above and below $T_{\min }$ reflecting the non-linear relationships involved (Ruel and Ayres, 1999). For example, assuming parameters used in the present model, hibernating in a thermally stable environment $2{ }^{\circ} \mathrm{C}$ above $T_{\min }$ increases overwinter energy expenditure by $35 \%$ whereas hibernating $2{ }^{\circ} \mathrm{C}$ below $T_{\text {min }}$ increases overwinter energy expenditure by $428 \%$.

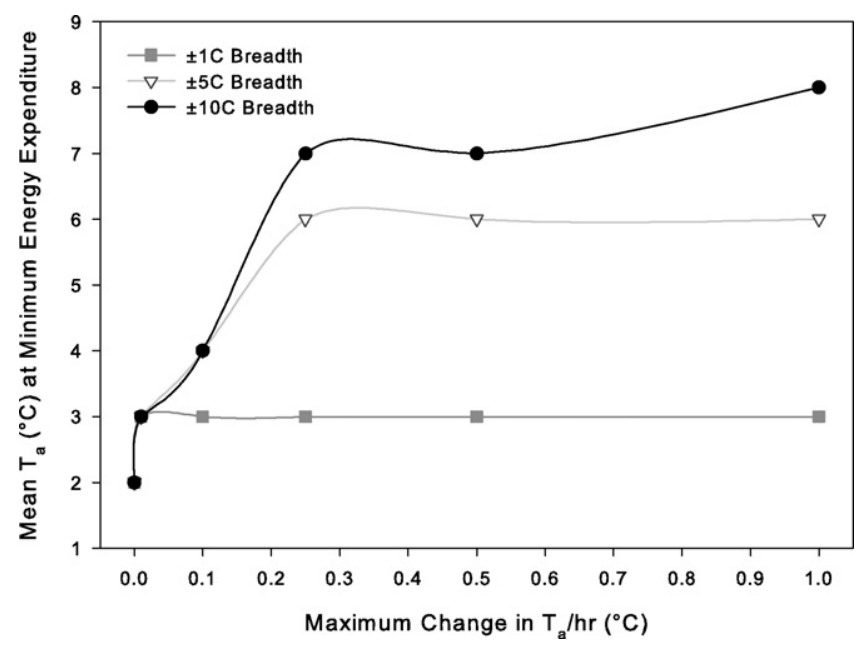

Fig. 2. The $T_{\text {mean }}$ which minimizes overwinter energy expenditure in a representative mammalian hibernator, Myotis lucifugus, at various rates of change in $T_{\mathrm{a}}$, assuming three different bounds for variation in $T_{\mathrm{a}}$. Thermal conductance was set at $0.055 \mathrm{ml} \mathrm{O}_{2} /\left(\mathrm{g} \mathrm{h}^{\circ} \mathrm{C}\right)$ (Humphries et al., 2002).

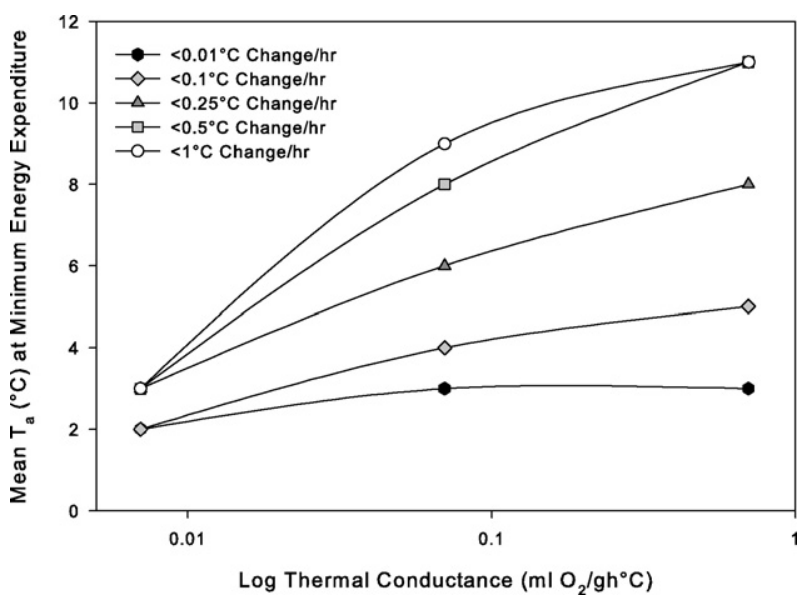

Fig. 3. The $T_{\text {mean }}$ which minimizes overwinter energy expenditure in a representative mammalian hibernator as thermal conductance increases, assuming $T_{\mathrm{a}}$ can vary by as much as $10^{\circ} \mathrm{C}$ around the mean $T_{\mathrm{a}}$ at five different rates of change.

Thermal conductance during hibernation is related to both body mass $\left(M_{\mathrm{b}}\right)$ and huddling. As thermal conductance increases, the slope relating TMR to $T_{\mathrm{a}}$ when $T_{\mathrm{a}}<T_{\min }$ becomes steeper and the relative energetic costs of hibernating above and below $T_{\min }$ change. The cost of hibernating in microclimates that occasionally drop below $T_{\min }$ will be relatively higher for individuals or species with higher thermal conductance, and thus the optimal temperature for energy conservation should approach, but never reach, $T_{\min }$ as $M_{\mathrm{b}}$ or cluster size increases. Importantly, the optimal temperature for energy conservation is always warmer than $T_{\min }$, even though low thermal conductance and thermally stable microclimates lead to an estimate of optimal $T_{\text {mean }}=T_{\text {min }}$ in our model (Fig. 3). This occurs because we modeled $T_{\mathrm{a}}$ in $1{ }^{\circ} \mathrm{C}$ increments and so true values, which are slightly above $T_{\min }$, round down to $T_{\min }$. Regardless, over the course of winter, it is energetically beneficial for all species to hibernate at $T_{\mathrm{a}} \mathrm{s}$ that are generally warmer than $T_{\min }$ unless the microclimate is perfectly stable thermally.

Although we did not model the energetic benefits of daily heterothermy, the principles of Jenson's inequality should also apply. In situations where $T_{\mathrm{a}} \approx T_{\min }$, the optimal selection of microclimates to conserve energy should be qualitatively the same as for hibernation; that is, animals should choose warmer microclimates. However, because microclimates experienced by daily heterotherms are often warm enough that $T_{\mathrm{a}}$ never falls below $T_{\min }$ (e.g., Willis et al., 2005; Willis and Brigham, 2007), daily heterotherms may experience the opposite situation and can conserve energy by choosing microclimates as cool as possible.

Our results directly contradict the notion that choosing microclimates where $T_{\mathrm{a}} \approx T_{\min }$ is the most energetically efficient expression of hibernation (Humphries et al., 2002; Dunbar and Tomasi, 2006), and add to a rapidly growing literature that takes an adaptive view of endothermic thermoregulation (Humphries et al., 2003; Boyles et al., 2007; Angilletta et al., forthcoming). These authors argue that a preference for microclimates warmer than $T_{\min }$ should be driven by non-energetic costs of hibernation. While the universality of the conclusions from these papers has been questioned recently (Stawski and Geiser, 2010), we show that even in the absence of non-energetic costs, endotherms hibernating anywhere that is not perfectly stable thermally should choose microclimates warmer than $T_{\min }$ to maximize energy conservation.

\section{Acknowledgements}

M. Brigham, J. Storm, and T. Tomasi provided helpful comments on the manuscript. This study was facilitated by funding from the British Ecological Society. 


\section{Appendix A. Supplementary data}

Supplementary data associated with this article can be found, in the online version, at doi:10.1016/j.ecolmodel.2010.03.018.

\section{References}

Angilletta, M.J., Jr., Cooper, B.S., Schuler, M., Boyles, J.G., forthcoming. The evolution of thermal physiology in endotherms. Front. Biosci.

Boyles, J.G., Brack Jr., V., 2009. Modeling survival rates of hibernating mammals with individual-based models of energy expenditure. J. Mammal. 90, 9-16.

Boyles, J.G., Dunbar, M.B., Storm, J.J., Brack Jr., V., 2007. Energy availability influences microclimate selection of hibernating bats. J. Exp. Biol. 210, 43454350.

Boyles, J.G., Storm, J.J., Brack Jr., V., 2008. Thermal benefits of clustering during hibernation: a field test of competing hypotheses on Myotis sodalis. Funct. Ecol. 22, 632-636.

Boyles, J.G., Willis, C.K.R., 2010. Could localized warm areas inside cold caves reduce mortality of hibernating bats affected by white-nose syndrome? Front. Ecol. Environ. 8, 92-98.

Brack Jr., V., 2007. Temperatures and locations used by hibernating bats, including Myotis sodalis (Indiana bat), in a limestone mine: implications for conservation and management. Environ. Manage. 40, 739-746.

Buck, C.L., Barnes, B.M., 1999. Temperatures of hibernacula and changes in body composition of Arctic ground squirrels over winter. J. Mammal. 80, 12641276.

Buck, C.L., Barnes, B.M., 2000. Effects of ambient temperature on metabolic rate, respiratory quotient, and torpor in an arctic hibernator. Am. J. Physiol. Regul. Integr. Comp. Physiol. 279, 255-262.
Dunbar, M.B., Tomasi, T.E., 2006. Arousal patterns, metabolic rate, and an energy budget of eastern red bats (Lasiurus borealis) in winter. J. Mammal. 87, 1096-1102.

Geiser, F., 2004. Metabolic rate and body temperature reduction during hibernation and daily torpor. Annu. Rev. Physiol. 66, 239-274.

Heldmaier, G., Ruf, T., 1992. Body temperature and metabolic rate during natural hypothermia in endotherms. J. Comp. Physiol. B: Biochem. Syst. Environ. Physiol. $162,696-706$.

Humphries, M.M., Thomas, D.W., Kramer, D.L., 2003. The role of energy availability in mammalian hibernation: a cost-benefit approach. Physiol. Biochem. Zool. 76, $165-179$.

Humphries, M.M., Thomas, D.W., Speakman, J.R., 2002. Climate-mediated energetic constraints on the distribution of hibernating mammals. Nature 418, 313-316.

Körtner, G., Geiser, F., 1998. Ecology of natural hibernation in the marsupial mountain pygmy-possum (Burramys parvus). Oecologia (Berl.) 113, 170-178.

Martin, T.L., Huey, R.B., 2008. Why “suboptimal” is optimal: Jensen's inequality and ecotherm thermal preferences. Am. Nat. 171, E102-E118.

Ruel, J.J., Ayres, M.P., 1999. Jensen's inequality predicts effects of environmental variation. Trends Ecol. Evol. 14, 361-366.

Stawski, C., Geiser, F., 2010. Fat and fed: frequent use of summer torpor in a subtropical bat. Naturwissenschaften 97, 29-35.

Thomas, D.W., Dorais, M., Bergeron, J., 1990. Winter energy budgets and cost of arousals for hibernating little brown bats, Myotis lucifugus. J. Mammal. 71, 475-479.

Vasseur, D.A., Yodzis, P., 2004. The color of environmental noise. Ecology 85, $1146-1152$.

Willis, C.K.R., Brigham, R.M., 2007. Social thermoregulation exerts more influence than microclimate on forest roost preferences by a cavity-dwelling bat. Behav. Ecol. Sociobiol. 62, 97-108.

Willis, C.K.R., Lane, J.E., Liknes, E.T., Swanson, D.L., Brigham, R.M., 2005. Thermal energetics of female big brown bats (Eptesicus fuscus). Can. J. Zool. 83, 871-879. 